\title{
General Psychiatry Association of anxiety-depressive disorders with irritable bowel syndrome among patients attending a rural family practice center: a comparative cross- sectional study
}

\author{
Alaa Adel Mohammed, Heba Ahmed Moustafa, Hebatallah Nour-Eldein, \\ Rabab Atta Saudi
}

To cite: Mohammed AA, Moustafa HA, Nour-Eldein $\mathrm{H}$, et al. Association of anxietydepressive disorders with irritable bowel syndrome among patients attending a rural family practice center: a comparative cross-sectional study. General Psychiatry 2021;34:e100553. doi:10.1136/ gpsych-2021-100553

Received 01 May 2021 Accepted 09 November 2021

Check for updates

(c) Author(s) (or their employer(s)) 2021. Re-use permitted under CC BY-NC. No commercial re-use. See rights and permissions. Published by BMJ.

Family Medicine Department, Suez Canal University, Ismailia, Egypt

Correspondence to Dr Rabab Atta Saudi; rabab.atta82@gmail.com

\section{ABSTRACT}

Background Comorbidity of irritable bowel syndrome (IBS) and psychiatric disorders is common, and the prevalence of at least one psychiatric disorder has been reported as high as $80 \%$ among patients with IBS. Aims To explore the association of anxiety-depressive disorders with IBS and its different subtypes, and to evaluate the associations of lifestyle habits, dietary habits and sleeping quality with IBS.

Methods A comparative cross-sectional study was conducted at the AL-Mahsama Family Practice Center, Ismailia, Egypt. It was carried out between October 2019 and October 2020. Participants were categorised into 175 patients with IBS, diagnosed using the Rome IV criteria, and 175 patients without IBS. A semistructured questionnaire was used to collect data on sociodemographic characteristics, lifestyle habits, dietary habits and sleep quality from both groups. The Hamilton Anxiety Rating Scale was used to assess anxiety symptoms, whereas the Beck Depression Inventory Second Edition was used to assess depression symptoms.

Results There was a high statistically significant difference between both groups with regard to age, education, occupation and socioeconomic status (SES), being a smoker, being physically inactive, having sleep disturbance and having irregular meals; being either obese or overweight was more reported in the IBS group. There was a high statistically significant difference in the rate of anxiety and depression between patients with and without IBS. Mild, moderate and severe anxiety were reported in $37.1 \%, 42.9 \%$ and $20.0 \%$ of patients with IBS while most (80.0\%) of the patients without IBS reported mild anxiety. Regarding depression, mild, moderate and severe depression were reported in $60.0 \%, 14.3 \%$ and $25.7 \%$ of the patients with IBS while most (82.9\%) of the non-IBS participants reported mild depression.

Conclusions The study shows a significant association between anxiety-depressive disorders and IBS, but no significant associations between anxiety-depressive disorders and IBS subtypes.

\section{INTRODUCTION}

Irritable bowel syndrome (IBS) is the most prevalent functional gastrointestinal disorder in the general population worldwide; further, IBS is the most common reason for referral to gastroenterology clinics, can be disabling and induces a major economic and social burden. ${ }^{1}$ According to the diagnostic criteria employed, IBS affects around $11 \%$ of the global population with variation by geographic region: the highest in South America (21.0\%) and the lowest occurring in South Asia (7.0\%). ${ }^{2}$ In Egypt, the prevalence was $34 \%$ in primary healthcare center attendees. $^{3}$

Several investigators have reported an association between eating habits, diet, sleep impairment, exercise and other lifestyle factors and IBS. ${ }^{4}$ Patients with IBS have significantly higher levels of psychiatric comorbidities than healthy individuals and are more susceptible to stress-related disorders; studies show a significant correlation between IBS and depression, generalised anxiety disorder, panic disorder, obsessive-compulsive disorder, bipolar disorder, somatisation and nonorganic sleep. ${ }^{5}$ The prevalence of at least one psychiatric disorder ranges from $40 \%$ to $60 \%$ and has been reported to be as high as $80 \%$ among patients with IBS. ${ }^{6}$

Depending on the Rome IV criteria, IBS is categorised into four subtypes (IBS diarrhoea (IBS-D) predominant, IBS constipation (IBS-C) predominant, IBS with alternating symptoms of constipation and diarrhoea or unsubtyped IBS), according to patients' reports of the proportion of time they have hard or lumpy stools versus loose or watery stools. ${ }^{2}$ IBS significantly reduces work productivity and health-related quality of life. Among patients with IBS, 13\%-88\% seek healthcare; patients who seek care have less social support and more distress than those who do not. ${ }^{7}$ 
A multidisciplinary approach is required to treat patients with IBS. Treatment is dependent on the dominant symptoms and individual basis. Not all patients with IBS respond to the same treatment. Particular attention should be paid to the aggravating factors in IBS such as nutrition, stress and psychological factors. Some patients with IBS respond well to non-pharmacological treatment, whereas others require pharmacological treatment. $^{8}$

Keeping in view the association of IBS with psychiatric disorders, as anxiety and depression influence IBS, patients with IBS should be screened for associated psychiatric disorders in order to develop a holistic approach for managing them and prompt referral to a psychiatrist for appropriate treatment. Furthermore, research suggested that in addition to the use of psychiatric drugs for clinical treatment of anxiety, we can consider regulating intestinal flora to relieve anxiety symptoms, particularly for patients with somatic diseases who are not suitable for the use of psychiatric drugs for anxiety treatment. ${ }^{9}$

Primary care is characterised by a biopsychosocial model of care that takes into account the context of the person's problem. These characteristics are especially important when managing chronic diseases, such as IBS, where the continuity of care is a high priority. Adult patients who present to their primary care physicians (PCP) with lower gastrointestinal (GI) tract disorders account for 1 in 20 of all primary care consultations. In the UK, up to $29 \%$ of patients with IBS are referred to a specialist but the majority of these will return to their PCP for long-term management. ${ }^{10}$ The importance of primary care providers (PCPs) in the diagnosis and management of GI disorders has been recognised in recent years, and it has been suggested that they have all of the available resources to ensure a high standard of care for their patients. ${ }^{11}$

Previous studies have demonstrated an association of IBS with psychiatric disorders, as anxiety and depression could have a profound influence on IBS. The association between IBS and psychiatric comorbidities has not been properly investigated in patients attending primary healthcare settings in Egypt. Thus, this study aimed to investigate the association of anxiety-depressive disorders with IBS, to assess the associations of anxiety-depressive disorders with IBS subtypes and to evaluate the associations of lifestyle habits, sleeping quality and dietary habits with IBS.

\section{METHODS}

\section{Study design and setting}

A comparative cross-sectional study was designed. Recruitment was conducted at AL-Mahsama Family Practice Center affiliated with the Faculty of Medicine, Suez Canal University. The study was carried out between October 2019 and October 2020.
Study participants

Inclusion criteria

The inclusion criteria were patients aged 18-50 years who had IBS, and patients aged 18-50 years who visited the AL-Mahsama Family Practice Center for any other medical problems, other than GI problems, as the chief complaint, and agreed to participate in the study.

\section{Exclusion criteria}

The exclusion criteria were (1) patients with onset of symptoms (less than 6 months), or those with any red flag criteria; (2) patients who have been diagnosed as terminally ill; (3) previously diagnosed patients with ulcerative colitis, Crohn's disease, diverticulitis, coeliac disease, peptic ulcer, oesophagitis, oesophageal ulcer, GI tumours and cholecystitis; (4) patients with a previous abdominal surgery before the actual diagnosis of IBS and (5) patients who refused to participate in the study.

\section{Sampling}

Sample size

The sample size was determined using the following equation:

$$
\mathrm{n}=2\left(\mathrm{Z}_{\alpha / 2}+\mathrm{Z}_{\beta}\right) \times\left(\mathrm{p}_{1}\left(1-\mathrm{p}_{1}\right)+\mathrm{p}_{2}\left(1-\mathrm{p}_{2}\right)\right) /\left(\mathrm{p}_{1}-\mathrm{p}_{2}\right)^{2}
$$

where:

$\mathrm{Z}_{\alpha / 2}$ is the critical value of the normal distribution at $\alpha / 2$ (eg, for a confidence level of $95 \%, \alpha$ is 0.05 and the critical value is 1.96 ).

$\mathrm{Z}_{\beta}$ is the critical value of the normal distribution at $\beta$ (eg, for a power of $80 \%, \beta$ is 0.2 and the critical value is $0.84)$.

$\mathrm{p}_{1}=45.67 \%$ (proportion of anxiety disorders as a psychiatric comorbidity among patients with IBS) ${ }^{12}$

$\mathrm{p}_{2}=30.71 \%$ (proportion of anxiety disorders as a psychiatric comorbidity among controls). ${ }^{12}$

For each group, the sample size (n) was 157. After adding a non-response rate of $10 \%$, the total sample size for each group was 173 patients and we recruited 175 patients for each group so that the total number of participants reached 350 .

\section{Sampling technique}

A simple random sampling was used to select the calculated number of the study sample. All patients requesting medical service at the AL-Mahsama Family Practice Center from 1 October 2019 to 29 February 2020 were approached and asked if they wished to participate in the study. If the patient showed interest, the design and purpose of the study were explained in simple language, and the patient signed an informed consent form agreeing to their official involvement in the research study.

\section{Study groups}

The enrolled patients were assigned into one of two groups. The flowchart is shown in figure 1.

- IBS group: includes (175) patients with IBS.

A list of 300 patients with IBS was made by the author from registered patients at the AL-Mahsama Family 


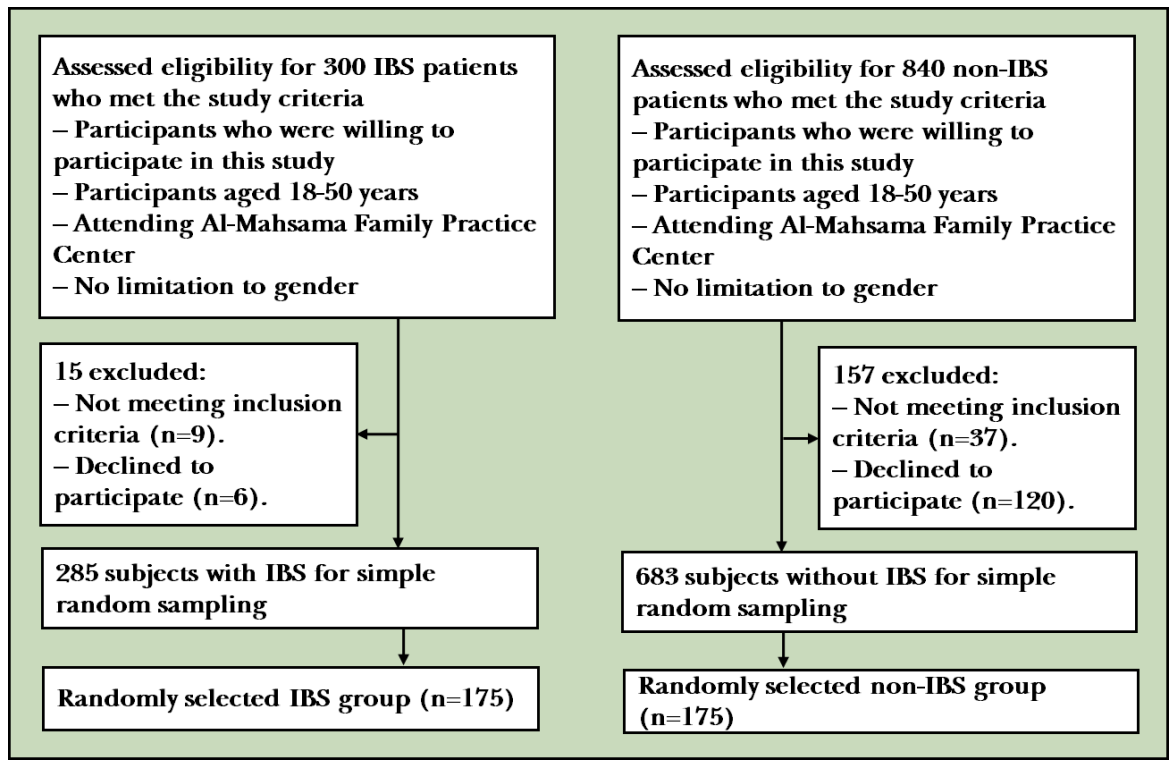

Figure 1 Flow diagram of participants. IBS, irritable bowel syndrome.

Practice Center from 1 October 2019 to 31 December 2019; 15 subjects were excluded after implementing the exclusion criteria, who did not respond to author's call or declined to participate. Then, according to the study criteria, 175 patients with IBS were selected using simple random sampling from 285 patients with IBS.

- Non-IBS group: includes (175) patients without IBS. A list of 840 patients who visited a family practice center for any other medical problems other than GI problems as chief complaint and who were not meeting the Rome IV criteria was made; 157 subjects were excluded after implementing the exclusion criteria, who did not respond to author's call or declined to participate. Then 175 patients without IBS were selected using simple random sampling among 683 patients without IBS according to the study criteria.

\section{Study tools}

Each participant was assessed by a semistructured questionnaire. The questionnaires were interviewer administered.

A. Sociodemographic characteristics. Socioeconomic status (SES) was assessed using a validated SES scale. This scale assesses SES based on seven domains, including education and culture, occupation, family, family possessions, economics, home sanitation and healthcare. The total score is 84 points and the SES will then be categorised into very low ( $\leq 21$ points), low (22-41 points), middle (42-62 points) and high (63-84 points). ${ }^{13}$

B. Lifestyle habits, sleep quality and dietary habits: for example, smoking, physical activity status, which was assessed according to the American College of Sports Medicine's guidelines for minimum activity requirements for being physically active. To achieve important health benefits, adults need 2 hours and $30 \mathrm{~min}$ (150 min) of moderate-intensity aerobic activity (eg, brisk walking) a week. ${ }^{14}$ Sleep quality was categorised based on the definition of insomnia: sleep disturbance (difficulty sleeping at least three times per week for at least 1 month) or good quality sleep (difficulty sleeping less than three times per week for 1 month). The term difficulty sleeping must meet the following criteria: (1) difficulty falling asleep, staying asleep or non-restorative sleep; (2) this difficulty exists despite having an adequate circumstance to sleep; and (3) this sleep disturbance is associated with daytime impairment or distress. ${ }^{15}$ Dietary habits were assessed as having meals on time, time spent eating, eating meals with family or outside the home, eating late-night snacks, picky eating habits and calculating the body mass index (BMI).

C. The Rome IV diagnostic criteria were used to diagnose patients with IBS; these include recurrent abdominal pain on average at least 1 day/week in the last 3 months, associated with two or more of the following criteria: (1) related to defecation, (2) associated with a change in the frequency of stool and (3) associated with a change in the form (appearance) of stool. These criteria should be fulfilled for the last 3 months with symptom onset at least 6 months before diagnosis. The sensitivity of Roma IV was $62.7 \%$ while specificity was $97.1 \%$, as assessed in a population sample of 5931 adults. Further, the patients with IBS were categorised into three subtypes: (1) IBS-C predominant, (2) IBS-D predominant and (3) mixed IBS (IBS-M). ${ }^{1}$

D. Hamilton Anxiety Rating Scale (HAM-A). The HAM-A scale was developed to assess the severity of anxiety symptoms; it is widely used in both clinical and research settings. The scale consists of 14 items, each defined by a set of symptoms, and measures both psychic anxiety (mental agitation and psychological distress) and somatic anxiety (physical complaints linked 
to anxiety). Each item is scored on a scale of 0 (not present) to 4 (severe), with a total score range of $0-56$; higher scores indicate greater anxiety. Scores less than 17 indicate mild anxiety, 18-24 moderate anxiety and 25-30 severe anxiety. The Arabic version of HAM-A was suitable and validated with the internal consistency of $0.921 .^{16}$

E. Beck Depression Inventory Second Edition (BDI-II). The BDI-II is a gold standard of self-report depression rating scales. The BDI-II is a widely used 21-item self-report inventory measuring the severity of depression. The scale measures the patient's mood and behaviour over the previous 2 weeks. Items are scored on a $0-3$ scale, with a total score of 0-63, where higher scores indicate greater depression severity. Scores in the range of 14-19 indicate mild depression, 20-28 moderate depression and 29-63 severe depression. The Arabic version of BDI-II shows good reliability with high consistency. The coefficient alphas range from 0.82 to $0.93 .{ }^{17}$

\section{Statistical analysis}

Patient data were entered into a Microsoft Excel sheet and then analysed using the Statistical Package for Social Sciences (SPSS) software program V.25.0. Data were presented in suitable tables. Categorical data were presented as frequencies and percentages. $\chi^{2}$ test and Fisher's exact test were used to compare categorical data between different groups. Binary logistic regression analysis was performed to ascertain the effects of factors (physical inactivity, sleep disturbances, irregular meals, overweight/obese, anxiety and depression) with IBS. Results were considered statistically significant at a $\mathrm{p}$ value $<0.05$.

\section{RESULTS}

Table 1 demonstrates the sociodemographic characteristics of study groups. $42.9 \%$ of the patients with IBS were in age group of 31-40 years, about two-thirds $(62.9 \%)$ of them were females and most $(77.1 \%)$ of them were married. Most $(71.4 \%)$ of the patients with IBS had high school or college education, nearly half $(48.6 \%)$ of them were employed and most $(88.6 \%)$ of them lived in rural areas. $71.4 \%$ of patients with IBS reported low or middle SES. Being unmarried, illiterate, a daily labourer and having very low and low SES were more reported in IBS group compared with non-IBS group. There was a high statistically significant difference between both groups with regard to age $\left(\chi^{2}=16.282, \mathrm{p}<0.001\right)$, education $\left(\chi^{2}=34.807, \mathrm{p}<0.001\right)$, occupation $\left(\chi^{2}=23.071, \mathrm{p}<0.001\right)$ and SES $\left(\chi^{2}=35.782, \mathrm{p}<0.001\right)$.

Table 2 shows the lifestyle and dietary habits in both study groups. Being a smoker, physically inactive and having sleep disturbance were reported more in the IBS group $(28.6 \%, 71.4 \%, 68.6 \%)$ compared with the nonIBS group $(14.3 \%, 57.1 \%, 42.9 \%) \quad\left(\chi^{2}=10.606, \mathrm{p}=0.001\right.$; $\left.\chi^{2}=7.778, \mathrm{p}=0.005 ; \chi^{2}=23.449, \mathrm{p}<0.001\right)$. There was a statistically significant difference between both groups with regard to the dietary habits (time spent eating: $\chi^{2}=19.054$, $\mathrm{p}<0.001$; having irregular meals: $\chi^{2}=23.844, \mathrm{p}<0.001$; and picky eating habits: $\left.\chi^{2}=17.690, p<0.001\right)$. Most of the IBS group patients spent 10-20 min in eating and had irregular meals with no picky eating habits $(54.3 \%, 71.4 \%$, $82.9 \%$ ), compared with most of the non-IBS group patients, who spent $<10 \mathrm{~min}$ in eating and had regular meals with picky eating habits $(51.4 \%, 54.3 \%, 54.3 \%)$. BMI showed significant differences between the study groups; obese and overweight patients were reported more in the IBS group $(48.6 \%, 28.6 \%)$ than in the nonIBS group $(31.4 \%, 25.7 \%) \quad\left(\chi^{2}=17.378, \mathrm{p}=0.001\right)$.

Table 3 shows that according to the HAM-A score, mild, moderate and severe anxiety were reported in $37.1 \%, 42.9 \%$ and $20.0 \%$ of patients with IBS, whereas most $(80.0 \%)$ of the patients without IBS reported mild anxiety. There was a high statistically significant difference between both groups with regard to the anxiety $(\mathrm{p}<0.001)$. According to BDI-II scores, there was a high statistically significant difference between both groups with regard to depression $(\mathrm{p}<0.001)$. Mild, moderate and severe depression were reported in $60.0 \%, 14.3 \%$ and $25.7 \%$ of patients with IBS, whereas most $(82.9 \%)$ of the non-IBS participants reported mild depression.

Table 4 demonstrates the association between anxietydepressive disorders with IBS subtypes. More than onethird $(38.6 \%)$ of the patients with IBS-C had moderate anxiety, nearly half (46.8\%) of the patients with IBS-D had moderate anxiety, while moderate anxiety was reported in $44.8 \%$ of the patients with IBS-M. In terms of depression, mild depression was reported in $62.9 \%, 51.1 \%$ and $63.8 \%$ of IBS-C, IBS-D and IBS-M patients, respectively. This table shows insignificant differences between IBS subtypes with regard to anxiety and depression $\left(\chi^{2}=9.389\right.$, $\mathrm{p}=0.052 ; \chi^{2}=4.060, \mathrm{p}=0.398$ ).

\section{DISCUSSION}

\section{Main findings}

This study revealed that there was a high statistically significant difference between IBS and non-IBS groups with regard to age, education, occupation and SES, being a smoker, being physically inactive, having sleep disturbance and having irregular meals; being either obese or overweight was more reported in the IBS group $(\mathrm{p}<0.05)$. There was a high statistically significant difference in the rate of anxiety and depression between patients with and without IBS. Mild, moderate and severe anxiety were reported in $37.1 \%, 42.9 \%$ and $20.0 \%$ of patients with IBS, whereas most $(80.0 \%)$ of the patients without IBS reported mild anxiety. Regarding depression, mild, moderate and severe depression were reported in $60.0 \%, 14.3 \%$ and $25.7 \%$ of patients with IBS, whereas most $(82.9 \%)$ of the non-IBS participants reported mild depression.

This study revealed that IBS is more common in the age group of $30-40$ years $(42.9 \%)$, which goes hand in hand with the study of Victor et al who mentioned that the highest percentage of patients $(38 \%)$ was in the range of 31-40 years of age ${ }^{18}$; however, Sayed and Abdelaziz stated that IBS is more common in the age 
Table 1 Sociodemographic characteristics of patients with and without IBS

\begin{tabular}{|c|c|c|c|c|c|c|}
\hline \multirow[b]{2}{*}{ Characteristics } & \multicolumn{2}{|c|}{$\begin{array}{l}\text { IBS } \\
(n=175) \\
\end{array}$} & \multicolumn{2}{|c|}{$\begin{array}{l}\begin{array}{l}\text { Non-IBS } \\
(n=175)\end{array} \\
\end{array}$} & \multirow[b]{2}{*}{$\chi^{2}$} & \multirow[b]{2}{*}{$P$ value } \\
\hline & n & $\%$ & $\mathbf{n}$ & $\%$ & & \\
\hline \multicolumn{7}{|l|}{ Age (years) } \\
\hline $18-30$ & 45 & 25.7 & 55 & 31.4 & \multirow[t]{3}{*}{16.282} & \multirow[t]{3}{*}{$<0.001^{*} \dagger$} \\
\hline $31-40$ & 75 & 42.9 & 40 & 22.9 & & \\
\hline $41-50$ & 55 & 31.4 & 80 & 45.7 & & \\
\hline Male & 65 & 37.1 & 60 & 34.3 & \multirow[t]{2}{*}{0.311} & \multirow[t]{2}{*}{$0.577 \dagger$} \\
\hline Female & 110 & 62.9 & 115 & 65.7 & & \\
\hline \multicolumn{7}{|l|}{ Marital status } \\
\hline Single & 15 & 8.6 & 10 & 5.7 & \multirow[t]{2}{*}{11.789} & \multirow[t]{2}{*}{$0.008^{*} \ddagger$} \\
\hline Married & 135 & 77.1 & 150 & 85.7 & & \\
\hline Illiterate & 15 & 8.6 & 10 & 5.7 & \multirow[t]{7}{*}{34.807} & \multirow[t]{7}{*}{$<0.001^{\star} \ddagger$} \\
\hline Can read and write & 0 & 0.0 & 0 & 0.0 & & \\
\hline Primary school & 5 & 2.9 & 0 & 0.0 & & \\
\hline Middle school & 15 & 8.6 & 15 & 8.6 & & \\
\hline High school & 70 & 40.0 & 40 & 22.9 & & \\
\hline College or some college & 55 & 31.4 & 105 & 60.0 & & \\
\hline Postgraduate degrees & 15 & 8.6 & 5 & 2.9 & & \\
\hline \multicolumn{7}{|l|}{ Occupation } \\
\hline Student & 10 & 5.7 & 12 & 6.9 & 23.071 & $<0.001^{*} \ddagger$ \\
\hline Rural & 155 & 88.6 & 155 & 88.6 & \multirow[t]{2}{*}{0.000} & \multirow[t]{2}{*}{$1.000 \dagger$} \\
\hline Urban & 20 & 11.4 & 20 & 11.4 & & \\
\hline \multicolumn{7}{|l|}{ SES } \\
\hline Very low & 20 & 11.4 & 0 & 0.0 & \multirow[t]{4}{*}{35.782} & \multirow[t]{4}{*}{$<0.001^{*} \ddagger$} \\
\hline Low & 55 & 31.4 & 30 & 17.1 & & \\
\hline Middle & 70 & 40.0 & 105 & 60.0 & & \\
\hline High & 30 & 17.1 & 40 & 22.9 & & \\
\hline
\end{tabular}

*Statistically significant at $\mathrm{p}<0.05$.

$+\chi^{2}$ test.

fFisher's exact test.

IBS, irritable bowel syndrome; SES, socioeconomic status.

group of 30 years and below $(42 \%) \cdot{ }^{12}$ Current results showed female predominance $(62.9 \%)$ in the prevalence of IBS; however, that was insignificant relation. Wang et al also reported that the prevalence of IBS in females was significantly higher than that in males. ${ }^{19}$ In our study, very low (11.4\%) and low (31.4\%) SES were more predominant in the IBS group compared with the non-IBS group. These results, very low $(0 \%)$ and low (17.1\%), agreed with Sayed and Abdelaziz who stated that IBS was associated with lower SES. ${ }^{12}$
This might be explained by the hypothesis that lowerincome is linked to poorer healthcare outcomes, increased life stressors and lower overall quality of life. However, Canavan et al found no association between SES and IBS. ${ }^{2}$ Further, Costanian et al reported that over $50 \%$ of IBS-positive cases had middle-to-high family income. ${ }^{20}$

Regarding lifestyle and BMI, this study showed significant differences between groups with regard to smoking, which was in agreement with the findings of Fujiwara et al, 
Table 2 Lifestyle and dietary habits in IBS group compared with non-IBS group

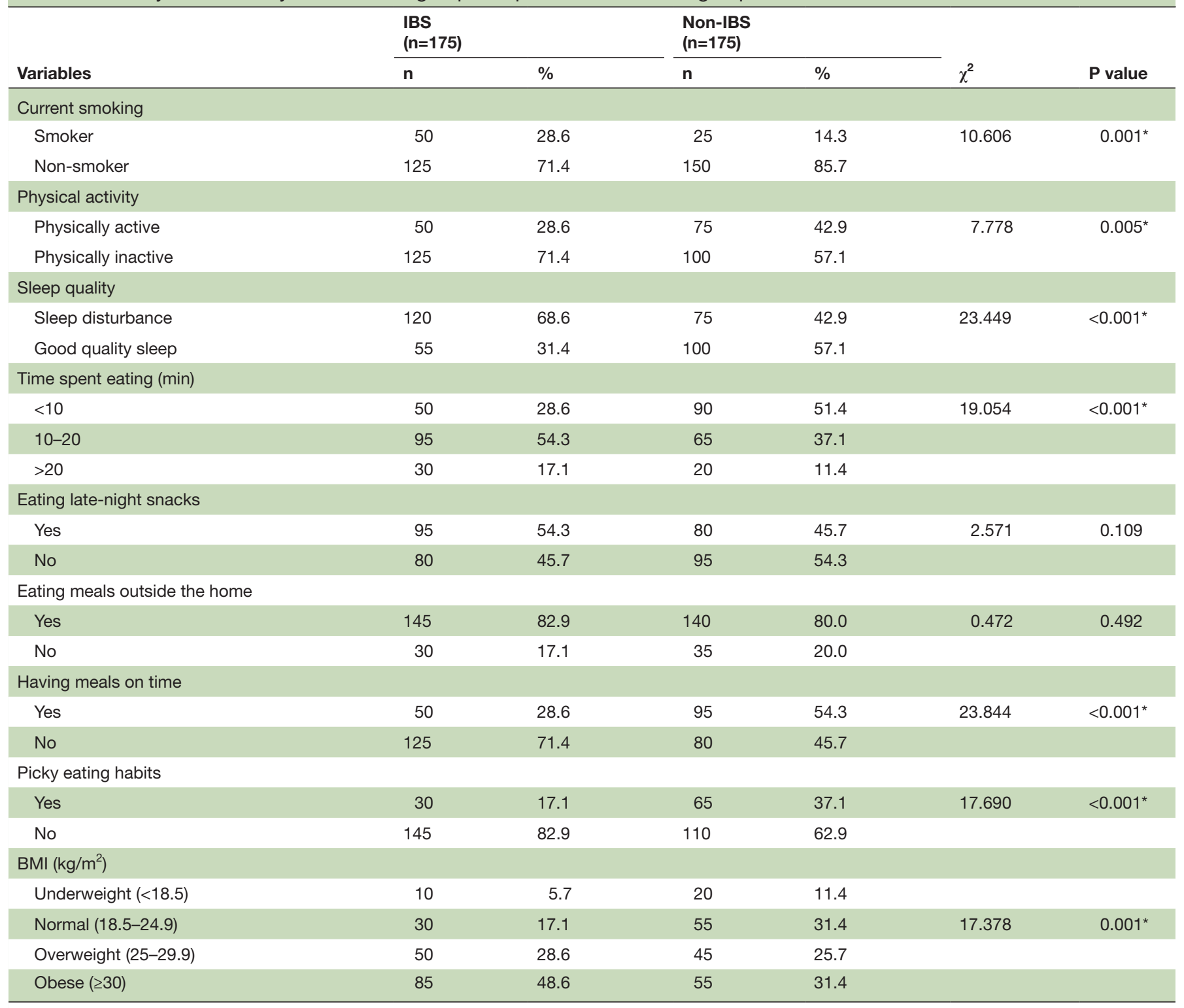

*Statistically significant at $\mathrm{p}<0.05$.

BMI, body mass index; IBS, irritable bowel syndrome.

Table 3 Anxiety-depressive disorders in patients with and without irritable bowel syndrome

\begin{tabular}{|c|c|c|c|c|c|c|}
\hline \multirow[b]{2}{*}{ Variables } & \multicolumn{2}{|c|}{$\begin{array}{l}\text { IBS } \\
(n=175)\end{array}$} & \multicolumn{2}{|c|}{$\begin{array}{l}\text { Non-IBS } \\
(n=175)\end{array}$} & \multirow[b]{2}{*}{$\chi^{2}$} & \multirow[b]{2}{*}{$P$ value } \\
\hline & $\mathbf{n}$ & $\%$ & $n$ & $\%$ & & \\
\hline \multicolumn{7}{|l|}{ Anxiety } \\
\hline Mild & 65 & 37.1 & 140 & 80.0 & 71.530 & $<0.001^{*}$ \\
\hline Moderate & 75 & 42.9 & 15 & 8.6 & & \\
\hline Severe & 35 & 20.0 & 20 & 11.4 & & \\
\hline \multicolumn{7}{|l|}{ Depression } \\
\hline Mild & 105 & 60.0 & 145 & 82.9 & 29.228 & $<0.001^{\star}$ \\
\hline Moderate & 25 & 14.3 & 20 & 11.4 & & \\
\hline Severe & 45 & 25.7 & 10 & 5.7 & & \\
\hline
\end{tabular}

*Statistically significant at $p<0.05$.

IBS, irritable bowel syndrome. who showed that cigarette smoking was significantly associated with IBS in the Japanese population. ${ }^{21}$ In contrast, Chatila et al showed no significant difference..$^{22}$ Regarding dietary habits, this study showed significant differences in time spent eating, picky eating habits and having irregular meals between the IBS group and the non-IBS group, which is in agreement with the findings of Hajishafiee $e t a l$, who showed subjects with IBS had irregular meal patterns, fast eating rates, and high intakes of fatty and spicy foods and caffeinated beverages and consumed fewer fruits and vegetables than healthy people. ${ }^{23}$

This study showed statistically significant differences between both groups with regard to depression $(p<0.05)$. Mild, moderate and severe depression were reported in $60.0 \%, 14.3 \%$ and $25.7 \%$ of patients with IBS, whereas most $(82.9 \%)$ of the non-IBS participants reported mild depression. These results are similar to the findings of Sayed and 
Table 4 Association of anxiety-depressive disorders with IBS subtypes $(n=175)$

\begin{tabular}{|c|c|c|c|c|c|c|c|c|}
\hline \multirow[b]{3}{*}{ Variables } & \multicolumn{6}{|c|}{ IBS subtypes } & \multirow[b]{3}{*}{$\chi^{2}$} & \multirow[b]{3}{*}{$P$ value } \\
\hline & \multicolumn{2}{|c|}{$\begin{array}{l}\text { IBS-C } \\
(n=70)\end{array}$} & \multicolumn{2}{|c|}{$\begin{array}{l}\text { IBS-D } \\
(n=47)\end{array}$} & \multicolumn{2}{|c|}{$\begin{array}{l}\text { IBS-M } \\
(n=58)\end{array}$} & & \\
\hline & $\bar{n}$ & $\%$ & $\bar{n}$ & $\%$ & $n$ & $\%$ & & \\
\hline \multicolumn{9}{|l|}{ Anxiety } \\
\hline Mild & 26 & 37.1 & 12 & 25.5 & 27 & 46.6 & \multirow[t]{2}{*}{9.389} & \multirow[t]{2}{*}{0.052} \\
\hline Moderate & 27 & 38.6 & 22 & 46.8 & 26 & 44.8 & & \\
\hline \multicolumn{9}{|l|}{ Depression } \\
\hline Mild & 44 & 62.9 & 24 & 51.1 & 37 & 63.8 & \multirow[t]{3}{*}{4.060} & \multirow[t]{3}{*}{0.398} \\
\hline Moderate & 12 & 17.1 & 7 & 14.9 & 6 & 10.3 & & \\
\hline Severe & 14 & 20.0 & 16 & 34.0 & 15 & 25.9 & & \\
\hline
\end{tabular}

IBS, irritable bowel syndrome; IBS-C, IBS constipation; IBS-D, IBS diarrhoea; IBS-M, mixed IBS.

Abdelaziz, which revealed that depressive disorder was more frequent in the IBS group $(57.48 \%)$ than in the control group (36.22\%); further, the rate of the severe type of depression in the IBS group $(46.57 \%)$ was higher compared with the control group (8.7\%). ${ }^{12}$ Also, Lee et al reported that the risk of depressive disorder was higher in the IBS cohort than in the comparison cohort. ${ }^{24}$ On the other hand, Shen et al cited that the self-reported psychological and psychosomatic symptoms of depression were encountered more frequently in participants with IBS but they added that depression and anxiety could potentially induce IBS (no cause-effect relationship). ${ }^{25}$

Regarding anxiety, this study showed statistically significant difference between groups and a high prevalence of moderate $(42.9 \%)$ and severe $(20.0 \%)$ anxiety in the IBS group compared with the non-IBS group $(8.6 \%, 11.4 \%)$, which is similar to the findings of Sayed and Abdelaziz, which revealed that the prevalence of anxiety disorders was higher in patients with IBS $(45.67 \%)$ compared with the control group $(30.71 \%)$; further, the prevalence of the severe type of anxiety in patients with IBS was higher $(53.45 \%) .{ }^{12}$ Grzesiak et al also reported that anxiety disorders were diagnosed in $47 \%$ of patients with IBS. ${ }^{26}$ However, Mikocka-Walus et al reported that the prevalence of psychological disorders is high in patients with IBS but their role in symptom reporting is uncertain. ${ }^{27}$

Regarding anxiety-depressive disorders in IBS subtypes, this study revealed insignificant differences between the IBS subtypes. This was in agreement with the findings of Victor $e t a l$ and Banerjee $e t a l$, who showed that there was no significant difference between IBS subtype groups in terms of anxiety and depression scores. ${ }^{18} 28$ Although research methodology, study population, measuring tools, sampling techniques and sample sizes are some factors that may influence the results of the studies, we may suggest that IBS has a significant relation with the existence of anxiety-depressive disorders. This might be considered as a clear evidence that all patients with IBS may suffer from some degree of anxiety-depressive disorders. IBS in our patients had some relation with their age, education, occupation, SES, smoking, sleep disturbance, irregular meals and being either obese or overweight.

\section{Limitations}

There may be some possible limitations to this study. For example, the self-reported nature of the questionnaire meant that recall and reporting bias was inevitable. Another limitation to this study is selection bias; participants were approached from one rural primary healthcare setting and, thus, did not truly represent a communitybased sample. Further, we could not establish causality in the association between anxiety-depressive disorders and IBS because this is a cross-sectional study. However, based on findings from previous studies that showed psychiatric disorders, such as anxiety and depression, could have a profound influence on IBS, we suggest that anxietydepressive disorders can be risk factors for IBS.

\section{Implications}

A patient-centred approach with a strong focus on effective communication between the physician and the patient has been recommended for the management of IBS and has been associated with improved outcomes, increased patient satisfaction and decreased utilisation of healthcare. For these reasons, a strong therapeutic relationship between the patient and his PCP is critical in the successful management of IBS. Keeping in view the high rates of psychiatric comorbidity in patients with IBS, all patients with IBS should be screened for associated psychiatric disorders in order to develop a comprehensive approach for managing these patients and timely referral to a psychiatrist for appropriate treatment.

Acknowledgements The authors would like to acknowledge all the participants for their cooperation.

Contributors AAM contributed to study design, data collection, statistical analysis, data interpretation and literature search. RAS, HAM and HN-E contributed to study design, statistical analysis, data interpretation, manuscript preparation and literature search. RAS is responsible for the overall content as guarantor.

Funding The authors have not declared a specific grant for this research from any funding agency in the public, commercial or not-for-profit sectors. 
Competing interests None declared.

Patient consent for publication Obtained.

Ethics approval The Ethics Committee of Faculty of Medicine, Suez Canal University, approved the study (code 3941). Informed consent was obtained from all participants included in the study.

Provenance and peer review Not commissioned; externally peer reviewed.

Data availability statement All data relevant to the study are included in the article or uploaded as supplementary information.

Open access This is an open access article distributed in accordance with the Creative Commons Attribution Non Commercial (CC BY-NC 4.0) license, which permits others to distribute, remix, adapt, build upon this work non-commercially, and license their derivative works on different terms, provided the original work is properly cited, appropriate credit is given, any changes made indicated, and the use is non-commercial. See: http://creativecommons.org/licenses/by-nc/4.0/.

\section{REFERENCES}

1 Soares RLS. Irritable bowel syndrome: a clinical review. World J Gastroenterol 2014;20:12144-60.

2 Canavan C, West J, Card T. The epidemiology of irritable bowel syndrome. Clin Epidemiol 2014;6:71-80.

3 Abdulmajeed A, Rabab MA, Sliem HA, et al. Pattern of irritable bowel syndrome and its impact on quality of life in primary health care center attendees, Suez governorate, Egypt. Pan Afr Med J 2011;9:6.

4 Miwa $\mathrm{H}$. Life style in persons with functional gastrointestinal disorders--large-scale internet survey of lifestyle in Japan. Neurogastroenterol Motil 2012;24:464-71.

5 Michael V, El Hamady M, El-Bakry S. A study of psychiatric comorbidities in irritable bowel syndrome. Egypt J Psychiatry 2018;39:140-9.

6 Singh P, Agnihotri A, Pathak MK, et al. Psychiatric, somatic and other functional gastrointestinal disorders in patients with irritable bowel syndrome at a tertiary care center. J Neurogastroenterol Motil 2012;18:324-31.

7 Agarwal N, Spiegel BMR. The effect of irritable bowel syndrome on health-related quality of life and health care expenditures. Gastroenterol Clin North Am 2011;40:11-19.

8 Radovanovic-Dinic B, Tesic-Rajkovic S, Grgov S, et al. Irritable bowel syndrome - from etiopathogenesis to therapy. Biomed Pap Med Fac Univ Palacky Olomouc Czech Repub 2018;162:1-9.

9 Yang B, Wei J, Ju P, et al. Effects of regulating intestinal microbiota on anxiety symptoms: a systematic review. Gen Psychiatr 2019;32:e100056.

10 khanbhai A, Sura DS. Irritable bowel syndrome for primary care physicians. BJMP 2013;6:a608.

11 Gikas A, Triantafillidis JK. The role of primary care physicians in early diagnosis and treatment of chronic gastrointestinal diseases. Int J Gen Med 2014;7:159-15.
12 Sayed T, Abdelaziz M. Psychiatric aspects of irritable bowel syndrome. Int J Curr Res 2019;11:1301-5.

13 El-Gilany A, El-Wehady A, El-Wasify M. Updating and validation of the socioeconomic status scale for health research in Egypt. East Mediterr Health J 2012;18:962-8.

14 U.S. Department of Health and Human Services. 2008 physical activity guidelines for Americans. Washington, DC: HHS, 2008. http:// www.health.gov/PAGuidelines

15 Roth T. Insomnia: definition, prevalence, etiology, and consequences. Journal Clinical Sleep Med 2007;3:S7-10.

16 Hallit S, Haddad C, Hallit R, et al. Removed: validation of the Hamilton anxiety rating scale and state trait anxiety inventory $A$ and $\mathrm{B}$ in Arabic among the Lebanese population. Clin Epidemiol Glob Health 2019;7:464-70.

17 Alansari BM. Internal consistency of an Arabic adaptation of the Beck depression INVENTORY-II with college students in eighteen Arab countries. Soc Behav Pers 2006;34:425-30.

18 Victor S, El-Hamady M, El-Bakry S. A study of psychiatric comorbidities in irritable bowel syndrome. Egypt J Psychiatry 2018;39:9-18.

19 Wang Y, Jin F, Chi B, et al. Gender differences in irritable bowel syndrome among medical students at inner Mongolia medical university, China: a cross-sectional study. Psychol Health Med 2016;21:964-74.

20 Costanian C, Tamim H, Assaad S. Prevalence and factors associated with irritable bowel syndrome among university students in Lebanon: findings from a cross-sectional study. WJG 2015;21:3628-35.

21 Fujiwara Y, Kubo M, Kohata Y, et al. Cigarette smoking and its association with overlapping gastroesophageal reflux disease, functional dyspepsia, or irritable bowel syndrome. Intern. Med. 2011;50:2443-7.

22 Chatila R, Merhi M, Hariri E, et al. Irritable bowel syndrome: prevalence, risk factors in an adult Lebanese population. BMC Gastroenterol 2017;17:137.

23 Hajishafiee M, Keshteli $\mathrm{AH}$, Saneei $\mathrm{P}$, et al. Healthy lifestyle score and irritable bowel syndrome: a cross-sectional study in adults. Neurogastroenterol Motil 2020;32:e13793.

24 Lee CG, Lee JK, Kang Y-S, et al. Visceral abdominal obesity is associated with an increased risk of irritable bowel syndrome. Am J Gastroenterol 2015;110:310-9.

25 Shen L, Kong H, Hou X. Prevalence of irritable bowel syndrome and its relationship with psychological stress status in Chinese university students. J Gastroenterol Hepatol 2009;24:1885-90.

26 Grzesiak M, Beszłej JA, Mulak A, et al. The lifetime prevalence of anxiety disorders among patients with irritable bowel syndrome. Adv Clin Exp Med 2014;23:987-92.

27 Mikocka-Walus A, Turnbull D, Moulding N, et al. Psychological comorbidity and complexity of gastrointestinal symptoms in clinically diagnosed irritable bowel syndrome patients. J Gastroenterol Hepatol 2008;23:1137-43.

28 Banerjee A, Sarkhel S, Sarkar R, et al. Anxiety and depression in irritable bowel syndrome. Indian J Psychol Med 2017;39:741-5.

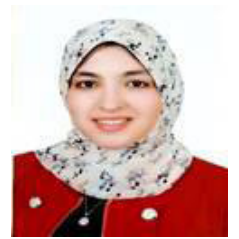

Alaa Adel Mohammed obtained a bachelor's degree in medicine and surgery from the faculty of medicine, Suez Canal University, Egypt, in 2015. At present, she is an assistant lecturer at the department of family medicine at the Suez Canal University. She had worked for 6 months from April 2017 to October 2017 as a primary care physician at the Sarabiom Family Practice Center, Ministry of Health, Egypt. Then, she worked as a family medicine resident at the Suez Canal University from October 2017 to 2020 . Her main research interests include primary care, mental health, women's health and geriatric health, and chronic diseases with a special interest in mental health and women's health. 